\title{
Variation of the $0^{+}$ion density during low and high solar activity as measured by the SROSS-C2 satellite
}

\author{
ANANNA BARDHAN \\ Department of Physics, FET, Manav Rachna International University, and Department of Physics, \\ Manav Rachna College of Engineering, Faridabad-121001, India \\ Department of Physics, Manav Rachna College of Engineering, Faridabad-121001, India \\ Corresponding author: Ananna Bardhan; e-mail: bardhan.ananna@gmail.com \\ DINESH KUMAR SHARMA \\ Department of Physics, Manav Rachna College of Engineering, Faridabad-121001, India \\ SARVESH KUMAR \\ Department of Physics, FET, Manav Rachna International University, Faridabad-121001, India \\ JAGDISH RAI \\ Department of Physics, Indian Institute of Technology, Roorkee-247667, India
}

Received August 6, 2013; accepted April 3, 2014

\begin{abstract}
RESUMEN
Se analiza la densidad del ion $\mathrm{O}^{+}$medida por el satélite SROSS-C2 durante el mínimo solar de $1995\left(\mathrm{~F}_{10.7}=77\right)$ y el máximo solar de $2000\left(\mathrm{~F}_{10.7}=181\right)$ para estudiar variaciones diurnas, estacionales, latitudinales y geomagnéticas. El área de estudio abarca una región comprendida entre los 5 y $35^{\circ}$ de latitud norte, y los 65 y $95^{\circ}$ de longitud oeste sobre la India a una altura de $\sim 500 \mathrm{~km}$ (región F2). El año 2000 muestra un aumento significativo en cuanto al promedio anual de densidad del ion $\mathrm{O}^{+} \mathrm{y}$ un aumento secundario posterior a la puesta del sol en comparación con 1995. Durante el día la ionización alcanza un máximo atribuido a la fotoionización. Sin embargo, la ocurrencia de un máximo posterior a la puesta del sol se atribuye a un fuerte aumento previo a la reversión en la desviación vertical $\mathrm{E} \times \mathrm{B}$. El efecto geomagnético de la actividad Kp a través del movimiento dinámico de la derivación $\mathrm{E} \times \mathrm{B}$ en los estudios de distribución de densidad del ion $\mathrm{O}^{+}$indica periodicidades de siete y nueve días en 1995 y 2000, respectivamente, así como dependencia polinómica de la densidad del ion $\mathrm{O}^{+}$en la actividad geomagnética Kp. Más aún, la estratificación de la densidad del ion $\mathrm{O}^{+}$ de acuerdo con la latitud $\left(5-35^{\circ} \mathrm{N}\right)$ indica alta densidad en latitudes medias $\left(12-24^{\circ} \mathrm{N}\right)$ en comparación con laltitudes bajas y altas, excepto en el invierno de 1995, que muestra un tendencia diferente (i.e., la densidad decrece conforme se incrementa la latitud).
\end{abstract}

\footnotetext{
ABSTRACT

The $\mathrm{O}^{+}$ion density measured by the SROSS-C2 satellite during solar minima (year 1995, $\mathrm{F}_{10.7}=77$ ) and maxima (year 2000, $F_{10.7}=181$ ) has been analyzed for studying diurnal, seasonal, latitudinal and geomagnetic variations. The study region covers an area encompassed between $5-35^{\circ} \mathrm{N}$ latitude and $65-95^{\circ} \mathrm{E}$ longitude over India at a $\sim 500 \mathrm{~km}$ altitude (F2 region). The year 2000 shows significant enhancement in the annual average of $\mathrm{O}^{+}$ion density and attainment of post sunset secondary enhancement compared to 1995 . Attributed to photoionization, daytime shows a maximum ionization compared to nigttime. However, attainment of post sunset secondary maxima is attributed to the strong pre-reversal enhancement in the vertical $\mathrm{E} \times \mathrm{B}$ drift. The effect of geomagnetic activity $\mathrm{Kp}$ through the $\mathrm{E} \times \mathrm{B}$ drift dynamic movement on $\mathrm{O}^{+}$ion density distribution studies
} 
indicates periodicities of seven and nine days in 1995 and 2000, respectively, and polynomial dependency of the $\mathrm{O}^{+}$ion density on geomagnetic activity $\mathrm{Kp}$. Further on, stratification of the $\mathrm{O}^{+}$ion density according to latitude $\left(5-35^{\circ} \mathrm{N}\right)$ indicates high density in mid-latitudes $\left(12-24^{\circ} \mathrm{N}\right)$ compared to high and low latitudes, except in the winter of 1995, which shows a distinct trend (i.e., density decreases with increasing latitude).

Keywords: $\mathrm{F} 2$ region, $\mathrm{O}^{+}$ion density, pre-reversal enhancement, $\mathrm{E} \times \mathrm{B}$ drift: geomagnetic activity $(\mathrm{Kp})$, solar minima and maxima.

\section{Introduction}

The primary source of ionization in the Earth's atmosphere is the interaction between solar radiation and neutral atoms and molecules. When high-energy photons collide with neutrals, they produce positive ions and free electrons. These ions and electrons have energies about tens of electron volts $(\mathrm{eV})$. These electrons can travel long distances and produce more ionization by collision with other neutral atoms and molecules. Solar extreme ultraviolet and X-ray radiations ionize the upper atmosphere to produce plasma in the Earth's ionosphere. It is well known that solar radiations change over different time scales, which induces corresponding variations in the ionosphere (Rishbeth and Garriott, 1969; Kawamura et al., 2002). For example, the most prominent solar cycle variation of solar radiations (Lean et al., 2001; Lundstedt et al., 2005) modulates significant 11-year changes in the ionosphere (Bilitza, 2000; Liu et al., 2006, 2009; Zhao et al., 2005; Afraimovich et al., 2008).

In addition to photoionization, the ionosphere is also controlled by recombination and dynamical processes. At equatorial and low latitudes, the F-region is characterized by a depression in ionization densities at the magnetic equator and two maxima on either side of the equator. Besides this well-known equatorial ionization anomaly (EIA), the equatorial ionosphere is known to exhibit some unique features such as the equatorial electrojet, the spread-F, etc. The horizontal orientation of the geomagnetic field lines at the equator and the shift between the geographic and geomagnetic equator are known to be the main reasons for observation of these features and their longitudinal variation. Martyn (1947) put forward the explanation that the E-region eastward electric field at the equator causes the F-region plasma to drift upward during the daytime. As the plasma is lifted to greater heights, it diffuses downward along geomagnetic field lines under the twin action of gravity and pressure gradients (Hanson and Moffett, 1966). A plasma fountain thus forms which moves ionization from the equator to the two anomaly crests. Variability occurring during the evening to post sunset and night hours have specific significance, after sunset electric field reverses, and velocity of drift enhances in opposite direction (pre-reversal enhancement), thereafter reverses its direction and reaches downward maximum (Horvath and Essex, 2002). During this process, when the F-region plasma drifts downwards the crest disappears. The low-latitude ionosphere at F-region heights has been studied quite extensively in the last three decades for its electrodynamics and resultant ionospheric features (Blanc and Richmond, 1980; Fejer, 1986, 1991). Mainly from the Jicamarca $\left(11.95^{\circ} \mathrm{S}, 76.87^{\circ} \mathrm{W}\right)$ experimental data, various important characteristics of the vertical F-region plasma drift are well known today (Fejer et al., 1991). From the results of the Sheffield University Plasmasphere Ionosphere Model (SUPIM) the behavior of equatorial plasma fountain and equatorial anomaly is well understood (Balan and Bailey, 1995; Balan et al., 1997; Bailey et al., 1997). The Jicamara data indicate the magnitude of the vertical F-region $\mathrm{E} \times \mathrm{B}$. Plasma drift velocity largely depends upon geophysical factors such as levels of magnetic activity, phases of solar cycles and seasons of the year (Fejer, 1991).

During daytime $\mathrm{O}^{+}$is produced in the F-region and diffuses upward in the topside. This flux of $\mathrm{O}^{+}$ into the topside causes the $\mathrm{O}^{+}$to $\mathrm{H}^{+}$transition height to rise above the expected in the presence of chemical equilibrium (Hoegy et al., 1991) . Meridional and zonal neutral winds in the F-region may act to raise or lower the height of the F-peak, which consequently enhances or reduces the $\mathrm{O}^{+}$flux into the topside ionosphere (West and Heelis, 1996; West et al., 1997). Truhlik et al. (2005) discussed solar activity in the global topside ion composition based on satellite data from OGO-6, AE-C, AE-E and IK-24 during the period from the late 1960s to the early 1990s. Bhuyan et al. (2002) simulated $\mathrm{O}^{+}$and $\mathrm{H}^{+}$ion density distributions in the topside F-region of the Indian low latitude ionosphere and 
compared the results with the density measurements made by the Indian SROSS-C2 satellite. Bhuyan and Borgohain (2005) studied diurnal, seasonal and latitudinal variation of ion concentrations as obtained from the SROSS-C2 satellite over Indian low and equatorial latitudes during solar minima. Borgohain and Bhuyan (2010) used the SROSS-C2 and the Taiwanese satellite FORMOSAT-1 over the Indian region to discuss solar cycle variations of ion densities over Indian low and equatorial latitudes.

In the present work, we have investigated diurnal and seasonal variations of the $\mathrm{O}^{+}$ion density during solar maxima (2000) and minima (1995) using SROSS-C2 satellite data, bearing in mind that diurnal and seasonal variability of the $\mathrm{O}^{+}$density depends on the magnitude of the vertical F-region $\mathrm{E} \times \mathrm{B}$ plasma drift velocity, which largely depends upon geophysical factors such as levels of magnetic activity and the phase of solar cycles. We have tried to discriminate the $\mathrm{O}^{+}$ion density according to latitude and geomagnetic activity Kp during low and high solar activity periods. This study brings out the $\mathrm{O}^{+}$ion density dependence on geomagnetic activity variations over Indian regions, which has not been reported and could help further understanding of the $\mathrm{O}^{+}$ion density distribution over Indian region. To study the phase effect of the solar cycle we have compared the $\mathrm{O}^{+}$ionization pattern and density during solar maxima (2000) and solar minima (1995). Further stratification of the $\mathrm{O}^{+}$ion density in accordance to latitudes over India for both years has been done.

\section{Instrumentation, data collection and analysis}

The ion densities data were recorded with the help of the Retarded Potential Analyzer (RPA) payload onboard the SROSS-C2 satellite, which was launched by the Indian Space Research Organization (ISRO) on May 4, 1994. The RPA payload consists of two sensors (i.e., electron and ion sensors) and associated electronics (Garg and Das, 1995). In addition, a spherical Langmuir probe is included and used for estimating the variation of spacecraft potential as the satellite spins. The electron and ion sensors have a planar geometry and consist of multigrid Faraday cups with a collector electrode. These mechanically identical sensors are mounted on the top deck, and they move in the cartwheel mode perpendicular to the spin axis of the spacecraft. Both sensors have different grid voltages suitable for the collection of electrons and ions, respectively. RPA sensors are $120 \mathrm{~mm}$ in diameter and $30 \mathrm{~mm}$ in height with an entrance aperture of $50 \mathrm{~mm}$. An annular shaped gold plated aluminum sheet of 50 mm diameter mounted flush on top of the sensor and connected to the satellite ground provides the return path for the current collected by the sensor. The ion RPA is used to drive a composite I-V curve for ions $\mathrm{O}^{+}, \mathrm{O}_{2}^{+}, \mathrm{H}^{+}$, and $\mathrm{He}^{+}$, and ion density is obtained from the curve fitting a non-linear curve method of iteration to the observed characteristics.

For the present study, satellite data have been selected for the solar minimum year (1995) and solar maximum year (2000) over the Indian region from 5 to $35^{\circ} \mathrm{N}$ latitude and from 65 to $95^{\circ} \mathrm{E}$ longitude, which corresponds to the maximum availability of the SROSS-C2 satellite passes over India. The measured ion density data have been analyzed for three different seasons: summer (May, June, July, August), winter (November, December, January, February), and equinoxes (March, April, September, October) during low and high solar activity periods. The data of geomagnetic index $\mathrm{Kp}$ have been obtained from the OMNIWeb Plus on the NASA website (http:// nssdc.gsfc.nasa.gov/space/). Variation as a function of day of the year has been studied for analyzing the variability of the $\mathrm{O}^{+}$ion density due to the $\mathrm{Kp}$ index for 1995 and 2000. For analyzing seasonal variation (summer, winter and equinox) values of the $\mathrm{O}^{+}$ density and Kp have been compared for both years.

\section{Results and discussions}

\subsection{Diurnal, seasonal, and annual variation}

The $\mathrm{O}^{+}$ion densities measured by the SROSS-C2 satellite are smoothened by computing hourly averages and calculating their standard deviations as shown in Figure 1a, b for low and high solar activity years, respectively. It is found that the peak value of the $\mathrm{O}^{+}$ion density is attained at 14:00 LT during both low and high solar activity years. Following this daytime maxima, the value of the $\mathrm{O}^{+}$ion density decreases gradually during the low solar activity period (1995) till 5:00 LT, whereas year 2000 data indicate a decrease in the $\mathrm{O}^{+}$ion density magnitude only till 19:00 LT (Fig. 1a, b). Thereafter, the density value suddenly increases during the post sunset period and peaks at 21.00 LT. After attainment of this secondary maxima, density value decreases gradually throughout the nighttime and minimum density is acquired around 5:00 LT. 


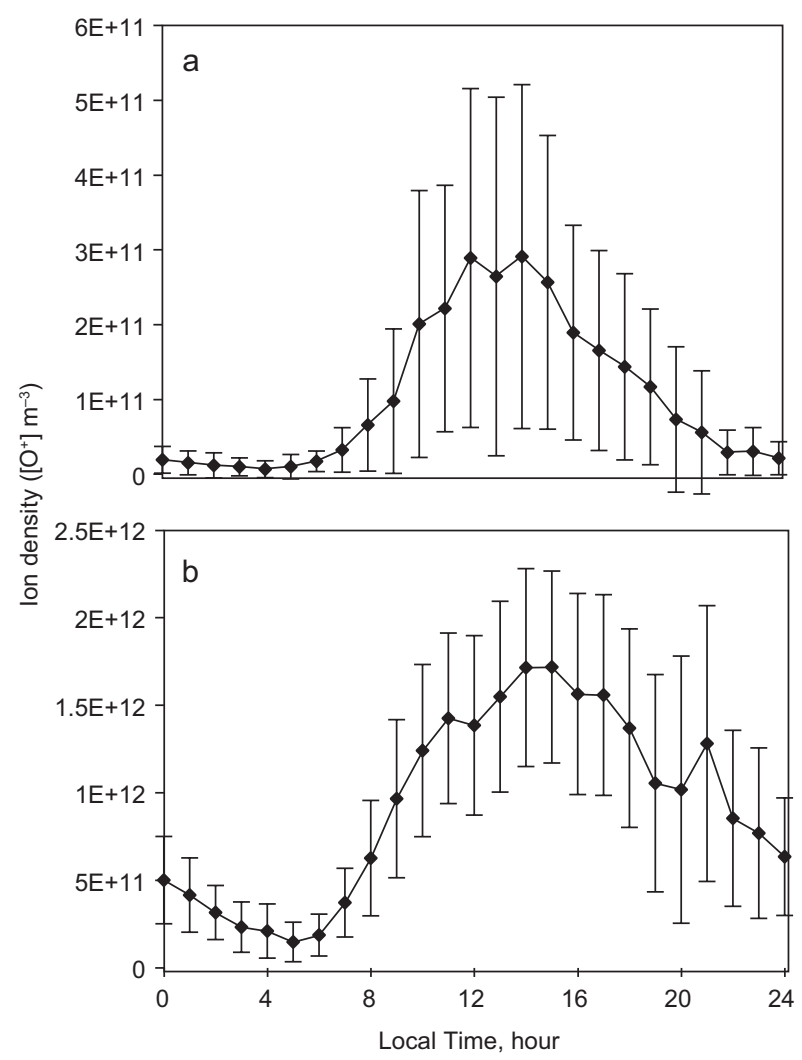

Fig. 1. Smoothened diurnal variations of the $\mathrm{O}^{+}$ion density along with the standard deviation (a) for low and (b) high solar activity periods, respectively.

The cause of this secondary enhancement of the $\mathrm{O}^{+}$ion density during the solar maxima year is the movement of the $\mathrm{E} \times \mathrm{B}$ drift in the F-region. The typical 24 hours diurnal variation states that the magnitude of velocity of the vertical F-region $\mathrm{E} \times \mathrm{B}$ drift increases until daytime peak velocity is attained, thereafter it decreases till sunset. During post sunset, drift velocity suddenly increases, then reverses and increases in reverse direction during nighttime (Fejer et al., 1991; Balan and Bailey, 1995; Balan et al., 1997; Bailey et al., 1997). Thus, attainment of a secondary peak during the solar high activity period is completely attributed to the movement of the $\mathrm{E} \times \mathrm{B}$ drift and is known as pre-reversal enhancement. However, there is no observable secondary or pre-reversal enhancement during low solar activity years.

Our data analysis indicates an enhancement nine times higher in average $\mathrm{O}^{+}$ion density during the high solar activity year compared to the low solar activity period. This supports the fact that there is a large increment in solar flux as the sun moves from a low to a high phase, and the sun is a primary cause of ionization.

This typical 24-hour trend can be largely modified by the seasonal and solar cycle variations. Thus we have analyzed $\mathrm{O}^{+}$ion density variability in accordance to three different seasons (summer, winter, equinoxes) during solar minima and solar maxima. Figure 2a-c, d-f represents diurnal and seasonal average variations of $\mathrm{O}^{+}$ion densities for three different seasons during solar minima and maxima, respectively. Figure $2 \mathrm{a}$ shows that the $\mathrm{O}^{+}$ion density gradually rises during summers and attains maximum ionization during daytime (10:00 LT), thereafter decreases gradually. During solar minima, a similar ionization pattern is noted in winters and equinoxes, as shown in Figure 2b, c, respectively. Detailed study of ionization patterns indicate a steeper slope in summers compared to winters and equinoxes. Comparatively analyzing seasons represented in Figure 2a-c, d-f highlights maximum $\mathrm{O}^{+}$density observed during equinoxes compared to winters and summers. During solar minima, the maximum density of $\mathrm{O}^{+}$ion is the highest observed during equinoxes having a value of $4.38 \mathrm{E}+11$, thereafter winters $(3.7 \mathrm{E}+11)$ and lastly summers $(2.03 \mathrm{E}+11)$. Similarly, the year 2000 has the highest value of $\mathrm{O}^{+}$ion density during equinoxes $(2.03 \mathrm{E}+12)$, however summers $(1.65 \mathrm{E}+12)$ and winters $(1.61 \mathrm{E}+12)$ show almost a similar ionization peak value. Figure $2 \mathrm{~d}$ indicates that maximum diurnal average $\mathrm{O}^{+}$ion density is administered during daytime (10:00-18:00 LT). A secondary enhancement has also been observed during late evening hours (21:00 LT). A similar kind of ionization pattern is observed in winters and equinoxes represented in Figure 2e, f, respectively, during the increased solar activity period of 2000. At the same time, it is interesting to note that secondary enhancement during winters (21:00 LT) is so high that it surpasses the daytime $\mathrm{O}^{+}$peak ionization value during solar maxima. Moreover, Figure 2d-f shows sharp secondary enhancements, while daytime maximum $\mathrm{O}^{+}$ionization peaks show a diffused pattern for all the seasons in solar maxima. Considering the argument that daytime drift velocities values show small variation with different seasons and solar variations, post sunset secondary enhancement exhibits a large variability. The pre-reversal enhancement of vertical upward $\mathrm{E} \times \mathrm{B}$ 

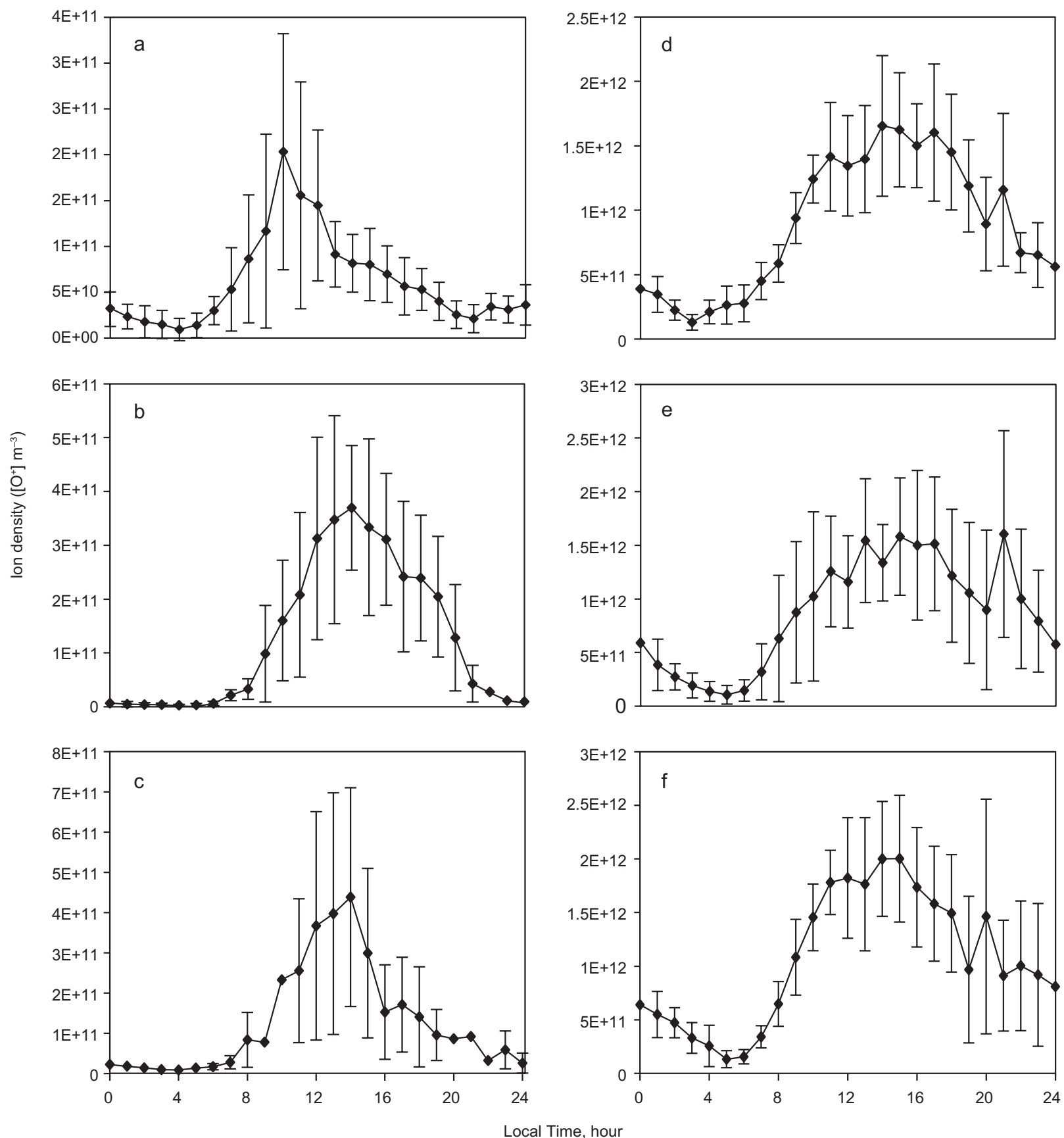

Fig. 2. Smoothened diurnal variation of the $\mathrm{O}^{+}$ion density in different seasons: summer (a and d), winter (b and e) and equinoxes (c and f) for low solar activity (a-c) and high solar activity (d-f) along with the standard deviation, respectively.

plasma drift velocity is most obvious in equinoxes and summer seasons when there is a low number of sunspots, and during all seasons in the presence of a high number of sunspots (Fejer et al., 1991). We tried to analyze data sets of the SROSS-C2 sattellite over the Indian region and found pre-reversal enhancement during all seasons in a high solar activity year, whereas during low solar activity there is no evening enhancement in winters. At the same time we could not find considerable evening enhancement in summers and equinoxes.

Data analysis also suggests that average ion density is almost equal for equinoxes and winters $(1.25 \mathrm{E}$ $+11,1.26 \mathrm{E}+11$, respectively), but is low during 
summers $(6.1 \mathrm{E}+10)$ in solar minima $(1995)$, while in solar maxima (2000) equinoxes show maximum average $\mathrm{O}^{+}$ion density $(1.05 \mathrm{E}+12)$ and almost similar average $\mathrm{O}^{+}$ion density values in winters and summers $(8.96 \mathrm{E}+11,8.87 \mathrm{E}+11$, respectively).

Hourly variation of $\mathrm{O}^{+}$ion density indicates that maximum ionization of the $\mathrm{O}^{+}$ion is obtained during midday for all seasons in low and high solar activity years except during winters (2000). During winters of solar maxima, the secondary peak of $\mathrm{O}^{+}$ion density is so high that it surpasses the daytime peak (Fig. 2b). This further suggests that plasma drift velocity during pre-reversal enhancement in winters of solar maxima is higher than the daytime peak velocity, which leads to conclude that movement of plasma is a more dominant factor in determining the $\mathrm{O}^{+}$density variation than photoionization during winter in 2000.

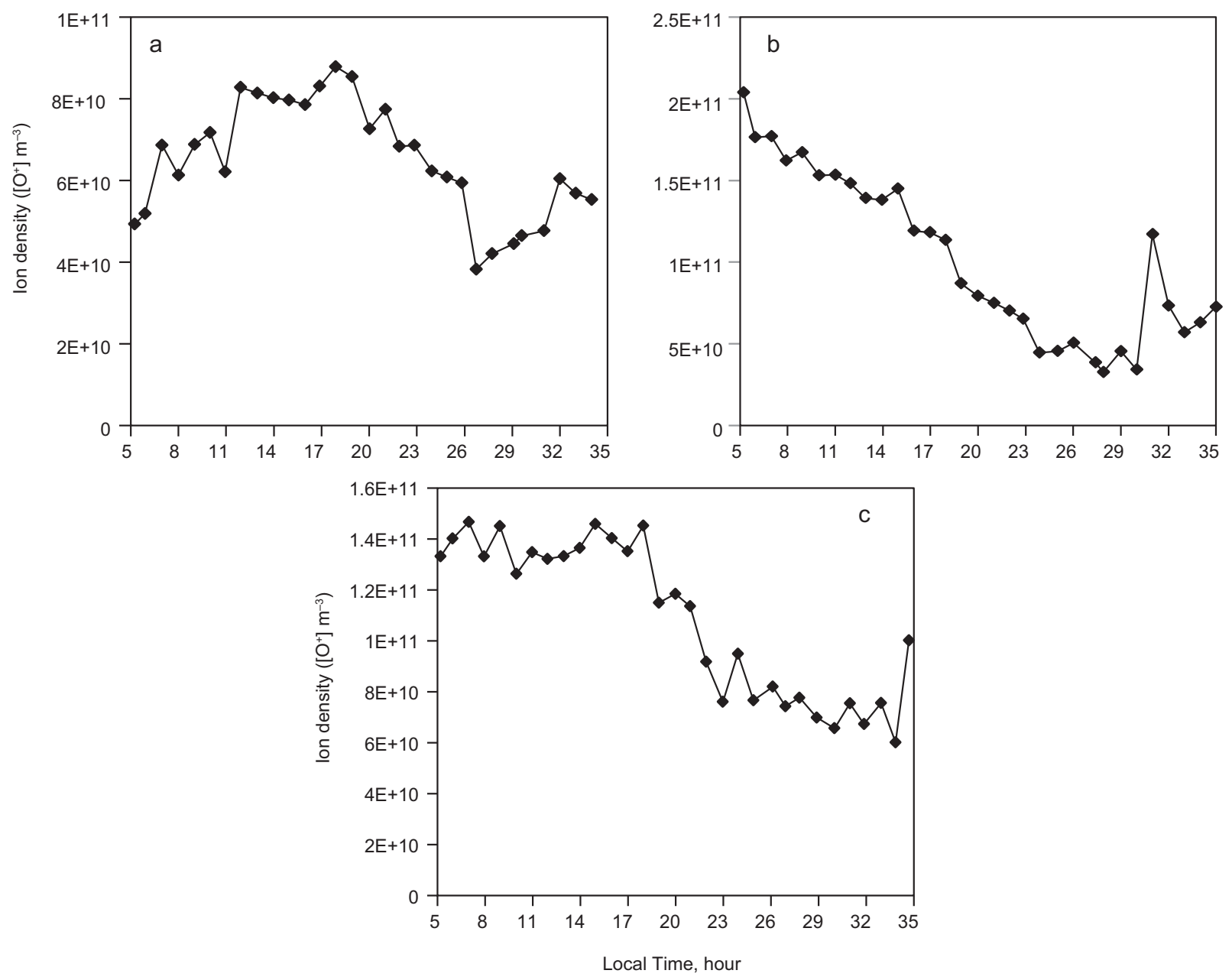

\subsection{Latitudinal variation}

$\mathrm{O}^{+}$ion density distributions have been studied in accordance with latitude over the Indian region. The latitude range $\left(5-35^{\circ} \mathrm{N}\right)$ we considered, which corresponds to the maximum availability of the SROSS-C2 passes, is comprised of highly variable F-region equatorial anomalies. Figures $3 \mathrm{a}-\mathrm{c}$ and $4 \mathrm{a}-\mathrm{c}$ show latitudinal dependence of the $\mathrm{O}^{+}$ion density during summer, winter and equinox in low and high solar activity years, respectively. $\mathrm{O}^{+}$density variation with latitude suggests high density in mid latitudes $\left(12-24^{\circ} \mathrm{N}\right)$ as compared to high and low latitudes over the Indian region. This variability is observed during all seasons (summer, winter, equinox) in 1995 and 2000, except for the winter of solar minima (1995), which shows a distinct trend (i.e., density decreases as latitude increases).

Fig. 3. Latitudinal variation of the $\mathrm{O}^{+}$ion density for three different seasons: (a) summers, (b) winters and (c) equinoxes during solar minima. 

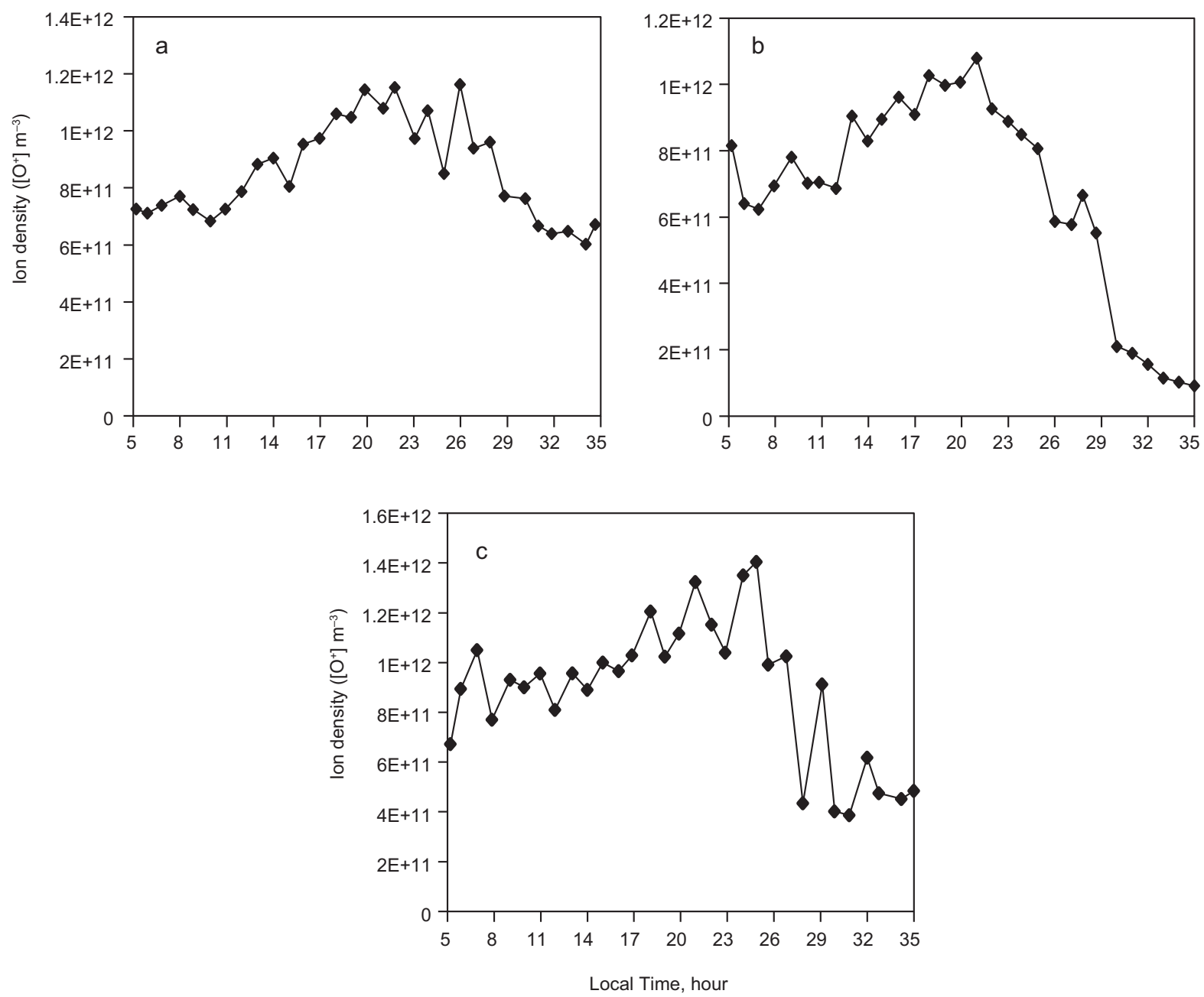

Fig. 4. Latitudinal variation of the $\mathrm{O}^{+}$ion density for three different seasons: (a) summers, (b) winters and (c) equinoxes during solar maxima.

\subsection{Variation of the $O^{+}$ion density with geomagnetic activity $\mathrm{Kp}$}

At high altitudes neutral composition, density, temperatures and winds may get affected due to periodic energy transfer from geomagnetic activity. This leads to changes in plasma neutral interactions, perturbing electron densities and total electron content (Padatella et al., 2010). At lower latitudes, apart from photoionization, force due to the $\mathrm{E} \times \mathrm{B}$ drift plays a key role in plasma density distribution; it is interesting to study the effect of geomagnetic activity $\mathrm{Kp}$ on the $\mathrm{O}^{+}$density distribution as the vertical component of geomagnetic field lines becomes insignificant and the nature of this interaction becomes more complex. In the present work authors have compared daily variations of the $\mathrm{O}^{+}$density with $\mathrm{Kp}$ patterns during high and low solar activity years (1995 and 2000, respec- tively) as shown in Figure 5. Periodicities of seven and nine days associated with the $\mathrm{Kp}$ index linked to solar coronal holes have been reported (Temmer et al., 2007). With careful observation it seems that the seven and nine days periodicity is significant in 1995 and 2000, respectively.

For further investigations, daily variations of the $\mathrm{O}^{+}$ion density and $\mathrm{Kp}$ for 365 days (1995) have been divided into $\sim 52$ cycles. Each cycle has seven consecutive days, and the average of $\mathrm{O}^{+}$and $\mathrm{Kp}$ for these cycles has been compared (Fig. 6a). A similar kind of analysis has been done for year 2000, expect for the fact that it has 40 cycles of nine-days periodicity (Fig 6b). It is quite notable that $\mathrm{O}^{+}$and $\mathrm{Kp}$ variations are in phase. In 1995, all seven days of the cycle are in phase with each other. However, in 2000 the 6th day of the cycle is out of phase. Otherwise, the Kp 


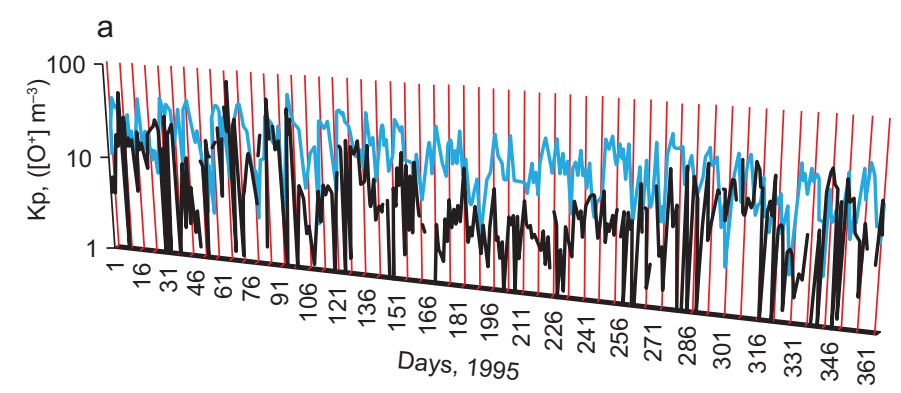

b $\mathrm{Kp}$

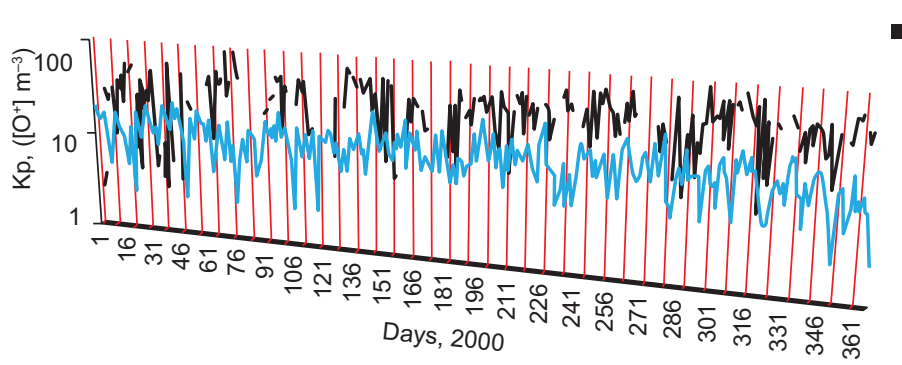

Fig. 5. Variations of $\mathrm{Kp}$ and $\mathrm{O}^{+} \times 1 \mathrm{E}+10$ as a function of day of the year for (a) 1995, (b) 2000. Vertical lines are marked at the seven and nine days interval in Figures 5a and 5b, respectively.
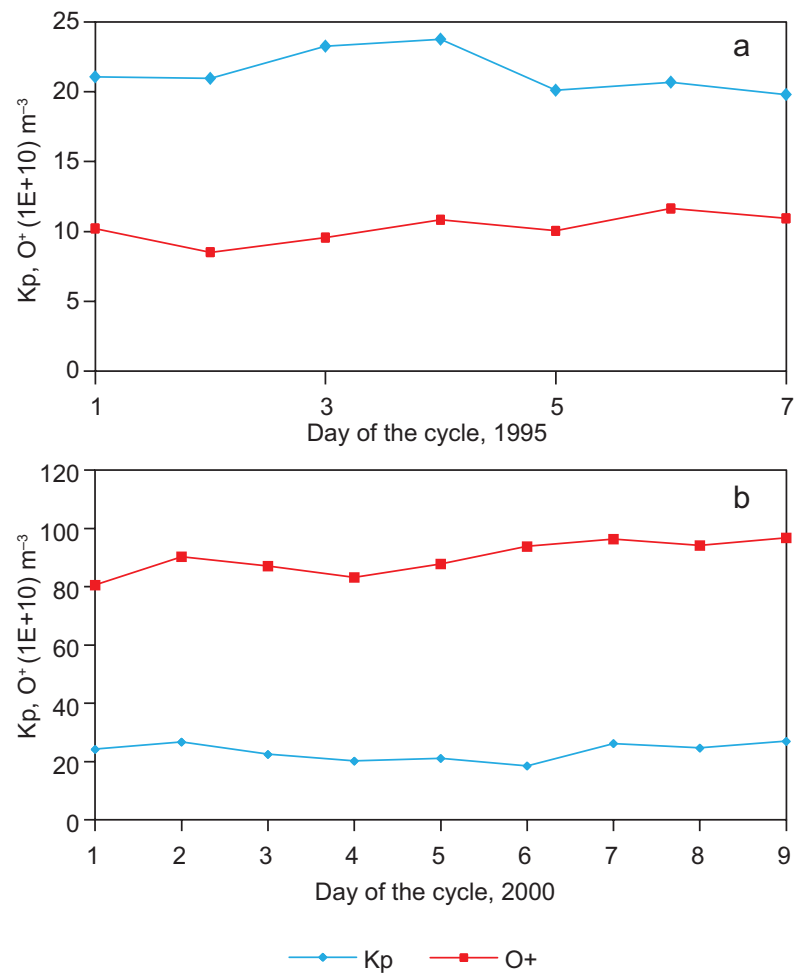

Fig. 6. Variation of $\mathrm{Kp}$ and $\mathrm{O}^{+} \times 1 \mathrm{E}+10$ as a function of day of the cycle for: (a) year 1995, (b) year 2000. and $\mathrm{O}^{+}$variation patterns are similar and in phase. Liu et al. (2010) reported the presence of periodic oscillations of about nine days in the number density of ions (Ni) during the declining phase of cycle 23, and multiple peaks as a function of day of the year in latitudinal profiles of nine day perturbations in $\mathrm{Ni}$. In the present work, seven-days periodicity is dominant during the initial phase of the solar cycle (1995), while during the solar maxima year 2000 nine-days periodicity is significant. In the present work, authors have also found multiple peaks within the seven and nine days periodicity consistent with Liu et al. (2010), but 7 and 9 days periodicities are most dominant. The origin of these periodicities is unknown, however they may originate due to planetary wave activity (Lastovika, 2006).

The region of analysis is low latitude, where geomagnetic field lines become more horizontal and have a negligible vertical component. Since the $\mathrm{K}$ index quantifies the horizontal component of the Earth's magnetic field and $\mathrm{Kp}$ is a weighed average from a network of geomagnetic observatories, any fluctuations in Kp would directly affect the $\mathrm{E} \times \mathrm{B}$ dynamic movement. From previous sections of this work, the deterministic role of the $\mathrm{E} \times \mathrm{B}$ dynamic movement in the $\mathrm{O}^{+}$density distribution is very evident. Thus, any change in 

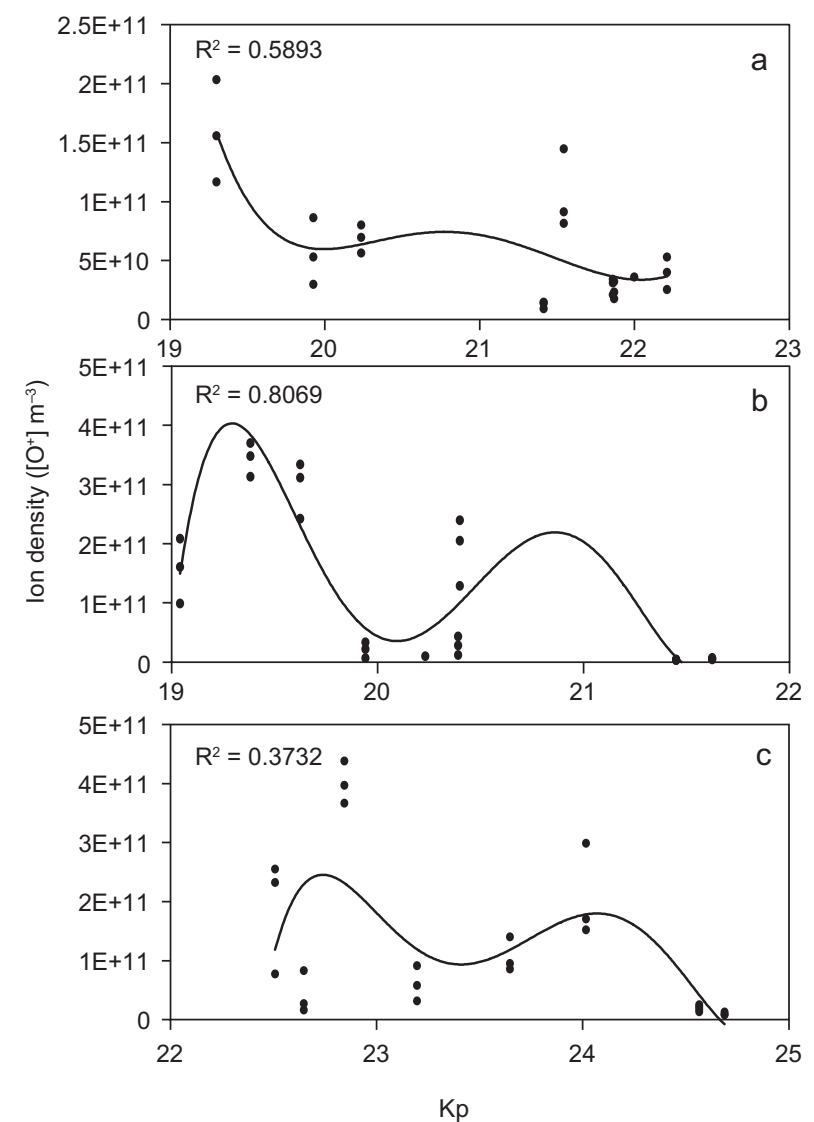

Fig. 7. Variations of the $\mathrm{O}^{+}$ion density with respect to geomagnetic index Kp during (a) summer, (b) winter and (c) equinox of 1995 (solar minima).

Kp would affect the $\mathrm{E} \times \mathrm{B}$ dynamic movement, adversely affecting the $\mathrm{O}^{+}$density distribution.

Figures $7 \mathrm{a}-\mathrm{c}$ and $8 \mathrm{a}-\mathrm{c}$ show variations of the $\mathrm{O}^{+}$ion density in accordance with $\mathrm{Kp}$ in summers, winters, and equinoxes in 1995 and 2000, respectively. However, Figure 7 shows a polynomial curve of order 5 with $\mathrm{R}^{2}=0.5893,0.8089$ and 0.3732 during summer, winter and equinox in 1995, exhibiting polynomial dependency for all the seasons except in equinoxes. Similarly, in 2000 Figure 8 shows polynomial dependency of order 5 with $\mathrm{R}^{2}=$ $0.6743,0.645$ and 0.792 during summers, winters and equinoxes, respectively.

Summarizing, the $\mathrm{O}^{+}$ion density dependence on $\mathrm{Kp}$ over the Indian region during solar minima and maxima suggests polynomial dependency on geomagnetic activity index $\mathrm{Kp}$, except for the equinox of 1995, which shows a poor correlation. The polynomial function suggests involvement of other factors apart from $\mathrm{Kp}$ in determining the $\mathrm{O}^{+}$density

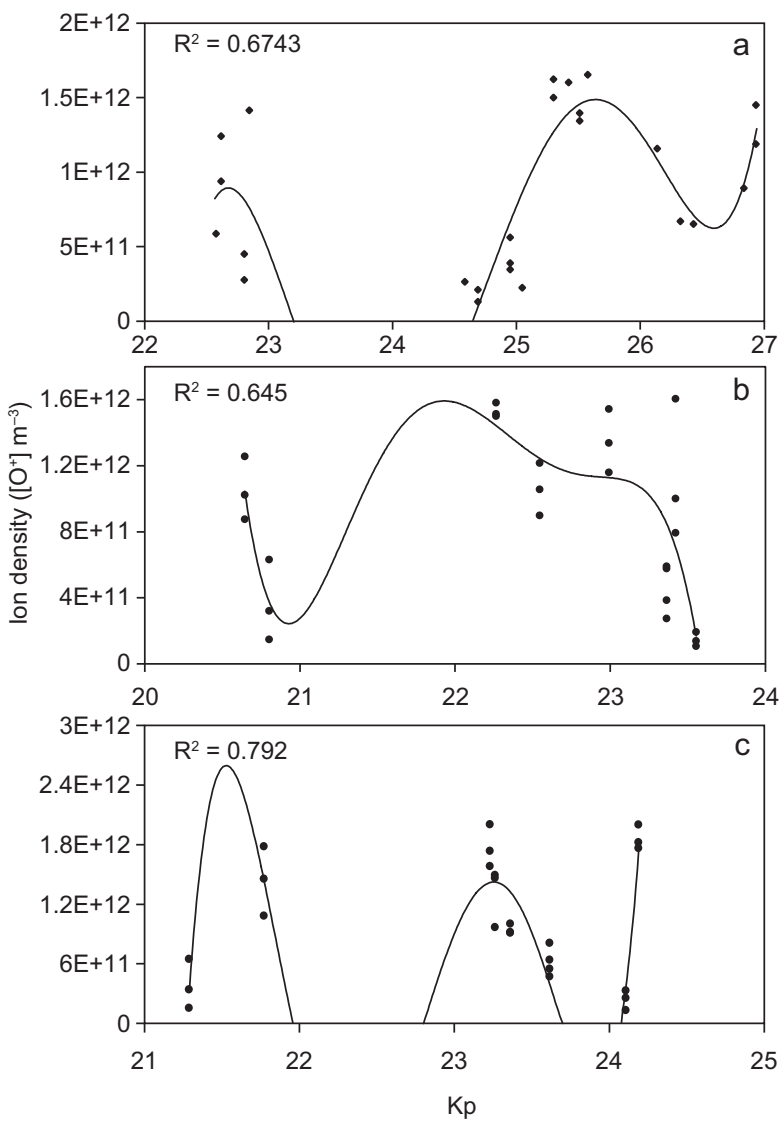

Fig. 8. Variations of the $\mathrm{O}^{+}$ion density with respect to geomagnetic index Kp during (a) summer, (b) winter and (c) equinox of 2000 (solar maxima).

distribution pattern over the Indian region. Accounting for other factors, like the effect of cosmic rays on the $\mathrm{O}^{+}$ion density would be negligible in this altitude region of the ionosphere. The ozone layer lies in the stratosphere, whose upper limit is $50 \mathrm{~km}$. Moreover, galactic cosmic rays and solar cosmic radiation are streams of highly energetic particles which penetrate deep down the atmosphere. In the ionosphere, the only layer modulated by cosmic rays is the D-region (Pulinets and Boyarchuk, 2004; Singh and Singh, 2010). Presently, the region in consideration is the F2 region ( $\sim 500 \mathrm{~km}$ of altitude). Authors do realize that there could be indirect reactions that would cause modulations in the $\mathrm{O}^{+}$ion density. Neutral winds and changes in neutral composition $\left([\mathrm{O}] /\left[\mathrm{N}_{2}\right]\right.$ ratio) also play an important role in determining the $\mathrm{O}^{+}$density distribution in the region. However, the effect of neutral composition and the indirect effect of cosmic rays are out of the scope of the this paper. Overall, Kp dependence through the $\mathrm{E} \times \mathrm{B}$ drift further enhances 
the importance of electrodynamic and geomagnetic variations in determining the $\mathrm{O}^{+}$density distribution over Indian sectors.

\section{Conclusions}

SROSS-C2 satellite data have been analyzed to study the temporal and spatial variations of the $\mathrm{O}^{+}$ion density for solar low and high activity periods. $\mathrm{O}^{+}$ion density attains its peak value during daytime in solar maxima as well as solar minima. With solar phase change from minima to maxima, there is a nine times enhancement of the average $\mathrm{O}^{+}$ion density, which supports the fact that photoionization is a primary cause of the $\mathrm{O}^{+}$ion production. Other key observations are the predominance of a secondary peak of $\mathrm{O}^{+}$ion density during the high solar activity year and the dependence of $\mathrm{O}^{+}$ion density distribution on geomagnetic activity index Kp. The secondary peak observed during the post sunset period in solar maxima year (2000) is attributed to the pre-reversal enhancement of electrodynamic drift. The existence of periodic modulation in low and high solar activity years further improves our understanding of solar and ionospheric interactions. Geomagnetic activity $\mathrm{Kp}$ dependence also suggests that the $\mathrm{O}^{+}$ion density over Indian latitude ranges highly depends on the plasma drift movement. The low latitude F-region ionosphere exhibits a large range of complex electrodynamic processes with broad range of temporal and spatial scales. Thus, the enhancement of solar flux or photoionization is not the only factor in determining the $\mathrm{O}^{+}$ion density profile, which is also due to the electrodynamic drift movement and geomagnetic activity fluctuations. Differential heating at different latitude ranges, which give rise to atmospheric motions on wide range of scales, further determines plasma distribution. The electrodynamic drift plays a substantial role in determining the spatial and tempo$\mathrm{ral}^{+}$ion density distribution over the Indian region.

\section{Acknowledgements}

Authors are thankful to All India Council for Technical Education (AICTE), New Delhi for financial assistance under the Research Promotion Scheme (RPS). We are also thankful to Prof. Naveen Prakash, Director-Principal of the Manav Rachna College of Engineering (MRCE), Faridabad for providing the necessary facilities, and The National Physical laboratory (NPL) for providing the satellite data.

\section{References}

Afraimovich E. L., E. I. Astafyeva, A. V. Oinats, Y. V. Yasukevich and I. V. Zhivetiev, 2008. Global electron content: A new conception to track solar activity. Ann. Geophys. 26, 335-344.

Bailey G. J., N. Balan and Y. Z. Su, 1997. The Sheffield University plasmasphere ionosphere model-a review. J. Atmos. Sol. Terr. Phys. 59, 1541-1552.

Balan N. and G. J. Bailey, 1995. Equatorial plasma fountain and its effects: Possibility of an additional layer. J. Geophys. Res. 100, 21421-21432.

Balan N., M. A. Abdu, K. I. Oyama, P. G. Richards, J. MacDougall and I. S. Batista, 1997. Equatorial plasma fountain and its effects over three locations: Evidence for an additional layer, the F3-layer. J. Geophys. Res. 102, 2047-2056.

Blanc M. and A. D. Richmond, 1980. The ionospheric disturbance dynamo. J. Geophys. Res. 85, 1669-1686.

Bhuyan P. K. and A. Borgohain, 2005. Diurnal, seasonal and latitudinal variation of ion concentrations as obtained from the SROSS-C2 satellite over Indian low and equatorial latitude during solar minimum. $A d v$. Space Res. 37, 919-927.

Bhuyan P. K., P. K. Kakoty and S. B. Singh, 2002. Theoretical simulation of $\mathrm{O}^{+}$and $\mathrm{H}^{+}$densities in the Indian low latitude F-region and comparison with observations. Ann. Geophys. 20, 1959-1966.

Bilitza D., 2000. The importance of EUV indices for the international reference ionosphere. Phy. Chem. Earth. Part C. 25, 515-521.

Borgohain A. and P. K. Bhuyan, 2010. Solar cycle variation of ion densities measured by SROSS-C2 and FORMOSAT-1 over Indian low and equatorial latitudes. J. Geophys. Res. 115, doi:10.1029/ 2009JA014424.

Fejer B. G., 1986. Equatorial ionospheric electric fields associated with magnetospheric disturbances. In: Solar wind magnetosphere coupling (Y. Kamide and J. Slavin, Eds.). Terra Scientific Publishing Lt. Tokyo, 519-545.

Fejer B. G., 1991. Low latitude electrodynamic drifts: A review. J. Atmos. Terr. Phys. 53, 677-693.

Fejer B. G., E. R. de Paula, S. A. Gonzales and R. F. Woodman, 1991. Average vertical and zonal F-region plasma drifts over Jicamara. J. Geophys. Res. 96, 13901-13906.

Kawamura S., N. Balan, Y. Otsuka and S. Fukao, 2002. Annual and semiannual variations of midlatitude ionosphere under low solar activity. J. Geophys. Res. 107, doi:10.1029/2001JA000267. 
Garg S. C. and U. N. Das, 1995. Aeronomy experiment on SROSS-C2. J. Spacecraft Technol. 5, 11-15.

Hanson W. B. and R. J. Moffett, 1966. Ionization transport effects in the equatorial F-region. J. Geophys. Res. 71, 5559-5572.

Hoegy W. R., J. M. Grebowsky and L. H. Brace, 1991. Ionospheric ion composition from satellite measurements made during 1970-1980. Adv. Space Res. 11, 173-782.

Horvath I. and E. A. Essex, 2002. Vertical E $\times$ B drift velocity variations and associated low-latitude ionospheric irregularities investigated with the TOPEX and GPS satellite data. Ann. Geophys. 2, 1017-1030.

Lastovicka J., 2006. Forcing of the ionosphere by waves from below. J. Atmos. Sol. Terr. Phys. 68, 479-497.

Lean J. L., O. R. White, W. C. Livingston and J. M. Picone, 2001. Variability of a composite chromospheric irradiance index during 11-year activity cycle and over longer time periods. J. Geophys. Res. 106, 10645- 10658.

Liu J., L. Liu, B. Zhao, W. Wan and R. A. Heelis, 2010. Response of the topside ionosphere to recurrent geomagnetic activity. J. Geophys. Res. 115, A12327, doi:10.1029/2010JA015810.

Liu L., W. Wan, B. Ning, O. M. Pirog and V. I. Kurkin, 2006. Solar activity variations of the ionospheric peak electron density. J. Geophys. Res. 111, A08304, doi:10.1029/2006JA011598

Liu L., W. Wan, B. Ning and M. L. Zhang, 2009. Climatology of the mean total electron content derived from GPS global ionospheric maps. J. Geophys. Res. 114, A06308, doi:10.1029/2009JA014244.

Lundstedt H., L. Liszka and R. Lundin, 2005. Solar activity explored with new wavelet methods. Ann. Geophys. 23, 1505-1511.
Martyn D. F., 1947. Atmospheric tides in ionosphere. I. Solar tides in F2-region. P. Roy. Soc. Lond. A Mat. 189, 241-260.

Padatella N. M., J. Lei, J. P. Thayer and J. M. Forbes, 2010. Ionosphere response to recurrent geomagnetic activity: Local time dependency. J. Geophys. Res. 115, A02301, doi: 10.1029/2009JA014712.

Pulinets S. and K. Boyarchuk, 2004. Ionospheric precursors of earthquakes. Springer, Berlin, Heidelberg, 315 pp.

Rishbeth H. and O. K. Garriott, 1969. Introduction to ionospheric physics. Academic Press, Amsterdam, 334 pp. (Int. Geophys Series, 14).

Singh D. and R. P. Singh, 2010. The role of cosmic rays in the earth's atmospheric processes. Pramana 74,153-168.

Temmer M., B. Vrsnak and A. M. Veronig 2007. Periodic appearance of coronal holes and the related variation of solar wind parameters. Sol. Phys. 241, 371-383.

Truhlik V., L. Trikosva, and J. Smilauer, 2005. Manifestation of solar activity in the global topside ion composition-a study based on satellite data. Ann. Geophys. 23, 2511-2517.

West K. H., R. A. Heelis and F. J. Rich, 1997. Solar activity variations in the composition of the low latitude ionosphere. J. Geophys. Res. 102, 295-305.

West K. H. and R. A. Heelis, 1996. Longitude variations in ion composition in the morning and evening topside equatorial ionosphere near solar minimum. J. Geophys. Res. 101, 7951-7960.

Zhao B., W. Wan, L. Liu, X. Yue and S. Venkatraman, 2005. Statistical characteristics of the total ion density in the topside ionosphere during the period 1996-2004. Ann. Geophys. 23, 3615-3631. 